\title{
New Advances in Environmental Friendly Materials
}

\author{
Nancy Lis Garcia ${ }^{1}$, Carlos Rodriguez ${ }^{2}$ and Norma D Accorso ${ }^{1,2 *}$ \\ ${ }^{1}$ CONICET- Universidad de Buenos Aires. Centro de Investigaciones en Hidratos de Carbono (CIHIDECAR), Buenos Aires, Argentina \\ ${ }^{2}$ Universidad de Buenos Aires, Facultad de Ciencias Exactas y Naturales (FCEyN), Departamento de Química Orgánica, Buenos Aires
}

*Corresponding author: Norma D Accorso, University of Buenos Aires, Argentina, South America

\section{Mini Review}

This last decade has been characterized by the acquisition of new materials based on the biomass, with the objective of replacing the materials obtained from petroleum derivatives, due to the high costs, added to the fact that they are non-renewable inputs and as a measure of the preservation of the environment [1]. In all areas of study has been this responsibility of searching for new and versatile materials. Packaging, medical materials, agro-industry, cosmetics, even energy applications, in all these fields are in constant search to be at the forefront and at the same time reduce all those materials that, during and at the end of their life cycle, cause damage to the environment, either due to the emission of greenhouse gases, or because they lack biodegradable and / or compostable properties [2]. Carbohydrates and lignin are the most abundant compounds in biomass and are used as biomolecules to replace oil derivatives. In this field, starch has many advantages over synthetic materials such as the possibility of obtaining thermoplastic films with important characteristics [3], in addition to being a renewable and low-cost resource. In cases where these materials have been limited by the mechanical properties and a greater permeation, this event has been improved with the incorporation of nanofillers of starch materials of biomass origin to overcome these disadvantages $[4,5]$.

Taking into account the bionanocomposites can be considered as the new emerging group of nanostructured hybrid materials. Bionanocomposites is defined as a mixture of naturally occurring polymer (biopolymer) and inorganic or organic filler materials that have at least one dimension on the nanometer scale. This new class of composites exhibits significant improvements in mechanical, barrier, and thermal properties, and dimensional stability. Furthermore, it also offers benefits like transparency, low density, better surface properties, good flow properties and recyclability
[6]. In this sense, Garcia et al. described the nanonocomposite capable to use in agricultural applications [7]. On the other hand, the proposal to use cellulose nanofillers from the bamboo inside polymer matrices is a promising and innovative way around materials for several applications [8].

The use of carbohydrate polymers associated with hydrophobic polymers need to perform chemical functionalized onto polymer matrix and the addition of natural nanocharges, have already been proven to completely change the mechanical properties of the whole material until its response to the hydrophobicity or hydrophilicity of same [9]. In the medicinal field the biopolymer-based hydrogels, such as chitosan or alginate are used to prepare new systems for drug delivery. These macromolecules are obtained from the renewable biomass and have properties as biocompatibility, non-toxicity and availability [6]. Moreover, oil production and transportation generate serious concern because accidental spills compromise the environment. Then, renewable resources emerge as our great ally. In matter of fact, biomass compounds, such as xanthan or guar gum are currently used to increase the reserves, increasing the amount of oil accessible for exploitation. Meanwhile, biomass sorbents (like straw or sawdust) have proved to be effective to absorb oil spills. So, research on biomass materials can be considered as a clever strategy to optimize yields and protect the environment until a definitive solution for oil problem can be found. All this description previously exposed, makes us glimpse the great field that remains to be explored around materials based on the renewable biomass. This is a field that arouses a lot of interest, and that it is the duty of all researches to develop in order to obtain the best materials that comply with current standards. It is important to know these new materials must be with the environment friendly to preservation the planet in which we live. 


\section{References}

1. Silvia Nair Goyanes, Norma Beatriz D Accorso (2017) Industrial Applications of Renewable Biomass Products. Past, Present, and Future, Editors: Springer.

2. Razza F, Farachi F, Degli Innocenti F (2010) Assessing the environmental performance and eco-toxicity effects of biodegradable mulch film, published in the conference proceedings of: LCA FOOD 2010 VII International Conference on Life Cycle Assessment in the Agri-food Sector, Bari (Italy) Proceedings 2: 378-383.

3. García NL, Famá L, Dufresne A, Aranguren M, Goyanes S (2009) A comparison between the physico-chemical properties of tuber and cereal starches. Food Res Int 42: 976-982.

4. Ribba L, Dufresne A, Aranguren MI, Garcia NL, Goyanes S (2009) PhysicoMechanical Properties of Biodegradable Starch Nanocomposites, Macromol. Mat Eng 294: 169-177.
5. García NL, Ribba L, Dufresne A, Aranguren M, Goyanes S (2011) Effect of glycerol on the morphology of nanocomposites made from thermoplastic starch and starch nanocrystals, Carbohyd Polym 84: 203-210.

6. García NL (2019) Bionanocomposites of Alginates, their Chemistry and Applications. In: Md Saquib Hasnain, Amit Kumar Nayak (Eds.), Alginates: Versatile Polymers in Biomedical Applications and Therapeutics $\left(1^{\text {st }}\right.$ edn), Apple Academic Press, USA.

7. Garcia NL, Fascio M, Errea MI, Dufresne A, D Accorso N (2018) Absorption of Siderite within a Chemically Modified Polylactic Acid based Composite Material for Agricultural Applications. J Polym Environ 26: 2173-2181.

8. Garcia NL, Rodriguez Ramirez CA, D Accorso NB (2018) Chemical modification of cellulose nanofibers from argentine cane tacuara (guadua angustifolia kunth). J Chem Eng Process Technol.

9. García NL, Lamanna M, D Accorso N, Dufresne A, Aranguren, et al. (2012) Biodegradable materials from grafting of modified PLA onto starch nanocrystals, Polym Degrad Stabil 97: 2021-2026.

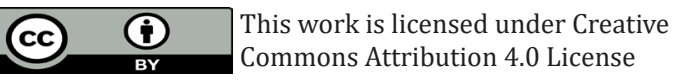

To Submit Your Article Click Here: Submit Article
DOI: $10.32474 /$ MAMS.2018.01.000105

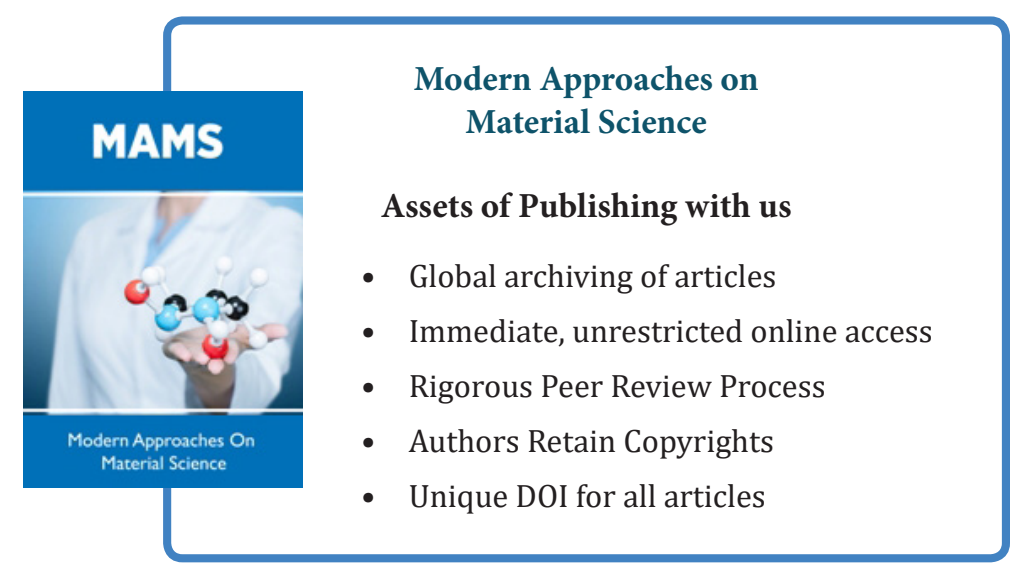

